Article

\title{
The Mechanical Properties of High Strength Reinforced Cured-in-Place Pipe (CIPP) Liner Composites for Urban Water Infrastructure Rehabilitation
}

\author{
Hyun Wook Ji ${ }^{1}$ (D), Sung Soo Yoo ${ }^{1, *}$, Jonghoon Kim ${ }^{2}$ and Dan Daehyun Koo ${ }^{3}$
}

1 Environmental and Plant Engineering Research Institute, Korea Institute of Civil Engineering and Building Technology, 283, Goyangdae-Ro, Ilsanseo-Gu, Goyang, Gyeonggi-Do 10223, Korea; jihyonwook@kict.re.kr

2 College of Engineering, Architecture, and Technology, Oklahoma State University, 509 Engineering North, Stillwater, OK 74078, USA; jongkim@okstate.edu

3 Department of Engineering Technology, Indiana University-Purdue University Indianapolis (IUPUI), 799 W. Michigan St. ET 314J, Indianapolis, IN 46202, USA; dankoo@iupui.edu

* Correspondence: yoosungsoo@kict.re.kr; Tel.: +82-10-8863-1569

Received: 30 May 2018; Accepted: 23 July 2018; Published: 26 July 2018

\begin{abstract}
Most urban areas in the world have water infrastructure systems, including the buried sewer and water pipelines, which are assessed as in need of extensive rehabilitation. Deterioration by many other factors affects structural integrity. Trenchless technologies such as Cured-in-Place Pipe (CIPP) are now applied in numerous projects while minimizing disturbance in an urban environment. The main purpose of this study is to develop a high strength CIPP material using various composite materials (e.g., glass fiber, carbon fiber, polyester felt, unsaturated polyester resin, and others). Composite samples were made of the materials and tested using three-point bend apparatus to find mechanical properties, which include the flexural modulus, strength, and deflection. A composite combination with glass fibers with thin felt layers shows the best results in mechanical properties. Flexural modulus is a key factor for CIPP liner thickness design. Glass fiber composite yields between four and nine times higher values than the minimum value specified in the American Society for Testing and Materials (ASTM) F1216. This study provides a fundamental baseline for high strength CIPP liners that are capable of using conventional curing technologies.
\end{abstract}

Keywords: Cured-in-Place Pipe (CIPP); pipe rehabilitation; composite material

\section{Introduction}

Sewer and water pipelines are key infrastructure systems in the urban environment, but the systems keep failing due to the structural degradation. Aging is the most significant reason for the structural deterioration of the buried infrastructure systems. Demand for capital improvement projects such as rehabilitation continuously increases as those systems keep failing. However, there is a huge gap in between the increasing rehabilitation demand and actual resources available. The structural assessment grade for sewer and water conveyance systems are D grade in the 2017 American society of civil engineers (ASCE) infrastructure report card [1]. There are over 800,000 miles of public sewers and 500,000 miles of private lateral sewers in the United States [1]. Trenchless technology is a group of engineering and construction methods, which minimize open-cut excavation. The primary benefit of the trenchless technology is to significantly reduce surface disruption during the construction phase [2]. Since its invention from the early 1970s, Cured-in-Place Pipe (CIPP) has been an effective rehabilitation technology, especially for sewers. However, research and development have been left behind, and the 
majority still uses traditional polyester felts. The main purpose of this study is to find high strength composite materials that are suitable for further development in CIPP application.

CIPP is a hollow cylinder containing a non-woven or woven fabric material, such as a felt layer, which is impregnated by a cured thermosetting resin. This new CIPP liner is formed within an existing pipe taking the geometry of and fits tightly to the existing pipe [3]. Resin is impregnated through layers of CIPP liners in a factory, then the liners are installed by using inversion or pulled in place technique at the construction site. The most common thermosetting resins used for sewer application is unsaturated polyester, and vinyl ester resin is especially used for the highly corrosive condition in need of chemical resistance liner. Glass fiber reinforced liners have developed for ultra-violet (UV) light curing application. The glass fiber reinforced liners are mainly installed by the pull-in installation method, and this application requires a calibration tube for the curing purpose. The glass reinforced CIPP has several advantages over the conventional felt based CIPP liner. The most significant advantage of the glass reinforced CIPP is its high strength. However, UV curing and use of a calibration tube make it challenging to improve construction productivity and cost competitiveness.

Although conventional CIPP is the most widely accepted and proven method for sewer rehabilitation, the lack of knowledge regarding the engineering performance of emerging new CIPP technology indicates that further research needs to address. CIPP for a water pipe rehabilitation application is also available in the industry. However, the pressurized water pipe application has gained less popularity mainly because of two reasons. Firstly, 100 percent solid epoxy resin, which is only approved by national sanitation foundation (NSF) 61 for the potable water CIPP, is much more costly than polyester resin. Secondly, the water pipe system has limited access for work and it is buried shallower than the sewer. In this case, the benefit of trenchless rehabiliation for the pressurized water pipe is less significant than the sewer. Flexural Strength and modulus are critical mechanical properties to determine the wall thickness of the CIPP liner. The wall thickness increases as loads and diameter of the existing pipe increases. Development of high flexural strength and modulus CIPP liner material is necessary to maximize flow capacity of the existing pipe, improve construction productivity on site, and reduce CIPP liner manufacturing cost. This study was seeking to identify composite materials attaining higher flexural strength and modulus with five percent maximum deformation. The main objectives of this study are: (1) to verify critical mechanical properties acquired from various CIPP liner composite sample tests and (2) to find the most effective composite layout.

\section{Previous Studies}

Many previous CIPP studies focused on case studies and retrospective performance assessment. Allouch et al. [4] conducted a retrospective evaluation of CIPP used in municipal gravity sewers. They retrieved testing samples from two cities installed over 20 years ago. They compared sample testing results with the original testing results at the time of the CIPP liner completion. Average flexural strength and modulus values show above a minimum threshold in American Society for Testing and Materials (ASTM) F1216 [3], but significant variation was verified between original test results and retrospective test results. It may occur during sample creation and tests. In their summary, the performance of the CIPP liners over 20 years indicates that life expectancy for the CIPP liners meets or may exceed the 50 years which has been taken as the nominal life expectancy in design.

The standard design guidelines are adopted for CIPP liner design calculation. A few examples of the widely accepted standard design guidelines are ASTM F1216 [3] in the United States, Sewerage Rehabilitation Manual (WRc SRM) [5] Type II in the United Kingdom, and ATV 127 [6] in Germany. The design methods are slightly different depending on the shape of the existing pipe, pressure status, and existing pipe condition. The primary function of those design methods is to determine the liner wall thickness, which provides the necessary structural capacity to resist the external and internal loads. Since the loads are relatively constant on the CIPP liners throughout the design life, the long-term mechanical properties are critical design factors to design the CIPP liner. The industry practice for the design life is typically 50 years in the long-term application. Therefore, CIPP design methods use 
long-term mechanical properties to calculate the thickness of the CIPP liner. Three-point load bending test is used for flexural strength and modulus of the CIPP liner sample. ASTM D790 [7] is a standard three-point load bend test.

CIPP mechanical properties are investigated to find long-term and short-term tensile strength, flexural strength, and flexural modulus. Riahi [8] studied long-term and short-term properties to ensure that the design requirements were met. Riahi's test results revealed that the Creep Retention Factor (CRF) varies by resin types and manufacturers. The ASTM F1216 [3] adopts a long-term flexural modulus for calculation of CIPP liner thickness design. Therefore, CRF value controls the design of the CIPP liner. A CRF of 0.5 ( $50 \%$ retention of short-term flexural modulus) is typically adopted as an industry standard practice [9]. CRF 0.5 is still used for non-reinforced CIPP using standard polyester resin system. On the contrary, a reinforced CIPP structure retains higher CRF values. North American Society for Trenchless Technology (NASTT) [10] present typical CIPP mechanical property values for gravity pipelines in good practice guidelines. They suggest CRF up to 80 percent for highly reinforced CIPP. A long-term creep test only confirms CRF. Nassar and Yousef [11] experimented and analyzed a long-term buckling behavior of a pipe under external hydrostatic pressure for at least 50 years. Their work shows that the current regression-based prediction for the long-term failure analysis is conservative and actual CIPP behavior is less likely failed with over 80 percent survival probability.

Glass fiber has been used as a lightweight reinforcement material for many composites such as polymer and concrete structures. Matthews [12] describe a $2400 \mathrm{~mm}$ diameter sewer rehabilitation using a partial glass fiber reinforced CIPP. A typical UV curing system is limited to $1200 \mathrm{~mm}$ in diameter. The described CIPP technology used as a hybrid to overcome the size limit and used a hot water curing system. Glass fiber reinforced polymer (GRP) is used instead of needle felt layer and increases flexural strength and modulus. Akinci et al. [13] conducted tests to compare GRP CIPP, and a conventional needle felt CIPP liner. The test results revealed that flexural modulus of the GRP yielded over $10 \mathrm{GPa}$. The test was limited by only comparing 100 percent GRP to 100 percent needle felt liner. Dong et al. [14] tested conventional Fiber Reinforced Polymer (FRP) composites using E glass and carbon fiber with epoxy resin. The composite was not intended for CIPP application. Epoxy is predominantly used for potable water rehabilitation. Installation and curing process for the epoxy resin is significantly different than polyester resin. Review of the previous studies and literature revealed that the insufficient level of knowledge would be available for reinforced CIPP composite liner mechanical property.

\section{Materials and Methods}

Flexural mechanical properties can be determined by three-point bend test, in which a loading nose deflects a specimen on a set span and rate until the specimen fractures. While loading the specimen, the underside is subjected to tensile stress, and the upper side is subjected to compressive stress. Any excessive stress of tensile, compressive or shear stress will cause fracture of the specimen. The test measures deflection of the sample and magnitude of loading to the sample. The three-point bending test is not able to identify a specific reason for the fracture.

Six composite groups were categorized as shown in Table 1. It shows that materials used for composites and their thickness with unit weight. Details of composite layer are described in Table 2, in Composition Layer Order column. Depending on the number of composite layers, materials, and thickness, total 21 group compositions were categorized as shown in Table 2. Multiple testing specimens were cut from the 21 group compositions.

ASTM F1216 [3] provides the minimum CIPP flexural modulus and strength for partially and fully deteriorated existing pipe conditions. The CIPP industry uses ASTM F1216 [3] as the prime reference for both design and manufacturing of the CIPP liner. Minimum flexural modulus and strength are respectively $1724 \mathrm{Mpa}(1.724 \mathrm{Gpa}$ ) and $31 \mathrm{MPa}$. Before polymerization (curing) of resin, the resin is liquid state to facilitate being impregnated in the felt liners. The impregnated liners shall be flexible enough to fit tight within the existing pipe. Polymerization hardens the resin and finally gains designed 
mechanical properties. The flexural strength of a conventional needle felt mostly based CIPP depends on the cured resin strength. Group No. 1 is made of high strength 100 percent unsaturated polyester resin, which has approximately two times of ASTM minimum flexural modulus. This polyester resin plate sample is used as a baseline for the further comparison to the test results of others.

Table 1. Sample Composition.

\begin{tabular}{|c|c|c|c|c|}
\hline Group Number & Composition Criteria & Materials & Thickness & Unit Weight \\
\hline 1 & Polyester Resin & $\begin{array}{l}\text { Unsaturated Polyester with styrene } \\
\text { monomer for CIPP (UP) }\end{array}$ & $\mathrm{N} / \mathrm{A}$ & $1.13 \mathrm{~g} / \mathrm{cm}^{3}$ \\
\hline \multirow{3}{*}{2} & \multirow{3}{*}{$\begin{array}{l}\text { Glass Fiber and } \\
\text { Polyester Resin }\end{array}$} & $\begin{array}{l}\text { Thin Roving Cross Glass } \\
\text { Fiber Mat (TG) }\end{array}$ & $0.5 \mathrm{~mm}$ & $0.9 \mathrm{~g} / \mathrm{cm}^{3}$ \\
\hline & & $\begin{array}{l}\text { Roving Cross Glass Fiber and } \\
\text { Chopped Strand Mat }(\mathrm{G})\end{array}$ & $1.0 \mathrm{~mm}$ & $0.96 \mathrm{~g} / \mathrm{cm}^{3}$ \\
\hline & & $\begin{array}{l}\text { Unsaturated Polyester with styrene } \\
\text { monomer for CIPP (UP) }\end{array}$ & $\mathrm{N} / \mathrm{A}$ & $1.13 \mathrm{~g} / \mathrm{cm}^{3}$ \\
\hline \multirow{3}{*}{3} & \multirow{3}{*}{$\begin{array}{l}\text { Carbon Fiber, Glass Fiber, } \\
\text { and polyester resin }\end{array}$} & $\begin{array}{l}\text { Roving Cross Glass Fiber and } \\
\text { Chopped Strand Mat }(G)\end{array}$ & $1.0 \mathrm{~mm}$ & $0.96 \mathrm{~g} / \mathrm{cm}^{3}$ \\
\hline & & $\begin{array}{l}\text { Unidirectional Carbon } \\
\text { Strands Mat }(\mathrm{C})\end{array}$ & $<0.5 \mathrm{~mm}$ & $1.81 \mathrm{~g} / \mathrm{cm}^{3}$ \\
\hline & & $\begin{array}{l}\text { Unsaturated Polyester with styrene } \\
\text { monomer for CIPP (UP) }\end{array}$ & $\mathrm{N} / \mathrm{A}$ & $1.13 \mathrm{~g} / \mathrm{cm}^{3}$ \\
\hline \multirow{3}{*}{4} & \multirow{3}{*}{$\begin{array}{l}\text { Glass fiber, Polyester Felt, } \\
\text { and Polyester Resin }\end{array}$} & $\begin{array}{l}\text { Roving Cross Glass Fiber and } \\
\text { Chopped Strand Mat }(\mathrm{G})\end{array}$ & $1.0 \mathrm{~mm}$ & $0.96 \mathrm{~g} / \mathrm{cm}^{3}$ \\
\hline & & Polyester Needle felt (F) & $2.0 \mathrm{~mm}$ & $0.3055 \mathrm{~g} / \mathrm{cm}^{3}$ \\
\hline & & $\begin{array}{l}\text { Unsaturated Polyester with styrene } \\
\text { monomer for CIPP (UP) }\end{array}$ & $\mathrm{N} / \mathrm{A}$ & $1.13 \mathrm{~g} / \mathrm{cm}^{3}$ \\
\hline \multirow{3}{*}{5} & \multirow{3}{*}{$\begin{array}{l}\text { Glass fiber, Thin polyester } \\
\text { Fabric, and polyester resin }\end{array}$} & $\begin{array}{l}\text { Roving Cross Glass Fiber and } \\
\text { Chopped Strand Mat }(\mathrm{G})\end{array}$ & $1.0 \mathrm{~mm}$ & $0.96 \mathrm{~g} / \mathrm{cm}^{3}$ \\
\hline & & Thin Polyester Woven Fabric (TF) & $<0.5 \mathrm{~mm}$ & $0.637 \mathrm{~g} / \mathrm{cm}^{3}$ \\
\hline & & $\begin{array}{l}\text { Unsaturated Polyester with styrene } \\
\text { monomer for CIPP (UP) }\end{array}$ & $\mathrm{N} / \mathrm{A}$ & $1.13 \mathrm{~g} / \mathrm{cm}^{3}$ \\
\hline
\end{tabular}

Glass and carbon fiber are frequently used to reinforce the strength of composite materials in other fields in the infrastructure construction. Glass reinforced CIPP liner was developed primarily for UV cure CIPP liners because UV light has limited wave penetration. The industry typically acknowledges that the UV penetrates approximately $10 \mathrm{~mm}$ in thickness. Therefore, development of a high strength liner is needed to meet the design/load requirements and maximum UV wave penetration depth. Hot water or steam curing CIPP rarely use high strength glass reinforced liners because of increasing material costs, complicating manufacturing process, the difficulty of resin impregnation, and lack of research for combining with other materials. Thus, the thickness of the CIPP significantly increases for the hot water or steam curing liners. Carbon reinforced rehabilitation method has been used for water transmission main rehabilitation, which is limited for person-entry access manual application applying carbon fiber sheets with epoxy resin primer and top coat. Although carbon fiber is seldom used for sewer application CIPP composite materials, this study includes carbon fiber for trial as a reinforcement substitute. Table 1 describes composition criteria for various materials used for CIPP composite samples. After impregnating unsaturated polyester resin in sheets of felt, glass, or carbon fiber, the composite liner is located between two stainless steel plates. The stainless steel plates are immersed and cured in hot water curing tub for $2 \mathrm{~h}$ at minimum of $80^{\circ} \mathrm{C}$ temperature.

Table 1 shows the unit weight of the composite component. Polyester felt is the lightest component due to micro-fiber structures containing a significant amount of air voids. During impregnation process, the resin fills in the air voids, and it is capable of carrying sufficient resin volume in the liner.

Figure 1 shows examples of the test specimens for both flexural and tensile strength measurement tests. Seven straight-bar shape specimens were cut from a composite sample plate in compliance to ASTM D790 [7] for a flexural property test. Specimens with concave-up in the middle section are prepared for tensile strength test, however this paper does not include results of the tensile test. 
According to ASTM F1216 [3], only pressurized pipe CIPP lining design such as water mains uses tensile strength for the design of lining thickness.

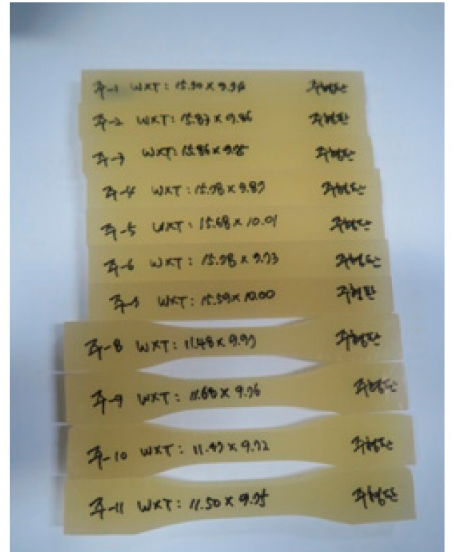

(a)

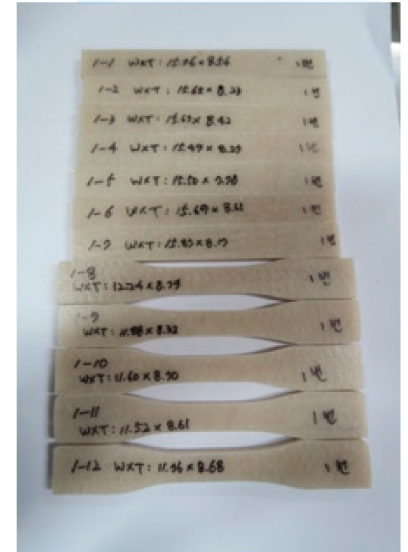

(b)

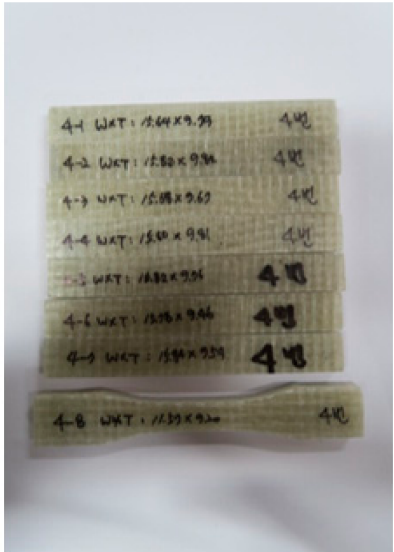

(c)

Figure 1. Cured-in-Place Pipe (CIPP) Samples for Mechanical Test: (a) Resin (Group No. 1); (b) Felt with Glass Fiber (Group No. 5); and (c) Glass Fiber (Group No. 2).

As stated earlier, the purpose of this study is to seek high strength and cost-effective CIPP composite. Mechanical properties used for CIPP design defines the magnitude of CIPP composite strength. Composite materials are described in Table 1, and composition layer order in Table 2 presents construction of the layers from the top of the surface where axial load applies with summary of mechanical properties. ASTM D790 [7] (Standard Test Methods for Flexural Properties of Unreinforced and Reinforced Plastics and Electrical Insulating Materials) is used as the test guideline. The ASTM D790 [7] testing method is typically known as three-point bend test. The three-point test applies the load from the top layer of the sample as shown in Figure 2.

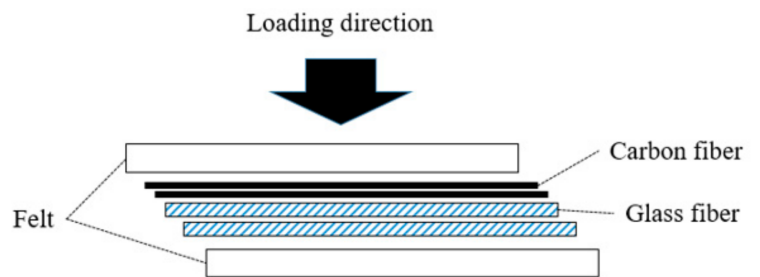

(a)

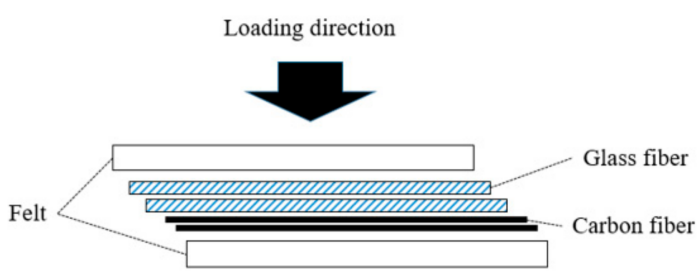

(b)

Figure 2. Carbon Fiber and Glass Fiber Composite Layers for Three Point Test: (a) Carbon fiber layered at the top of the composite and (b) Carbon fiber layered at the bottom of the composite.

As shown in Figure 2, axial load applies directly over the top of the specimen. Elastic deformation creates compressive and tensile stress areas through the cross-section. Strength in the compression and tension area varies depending on the strength of carbon and glass fiber layers in the composite. To verify the difference of structural capacity in different layer orders, samples in the group No. 3 were alternatively layered the carbon and glass fiber sheets.

\section{Results}

Flexural strength and modulus are two primary mechanical properties for non-pressurized CIPP design. Two selected mechanical properties are used to determine structural capacity of the CIPP against an external load. Flexural strength is defined as the stress in a CIPP sample just before it fails. 
Flexural modulus is determined from the maximum slope of a stress-strain curve produced by the load-strain graph. Table 2 presents the summary of average flexural strength and modulus in $23 \mathrm{CIPP}$ sample composites acquired from total 122 testing specimens.

Table 2. Summary of Mechanical Properties.

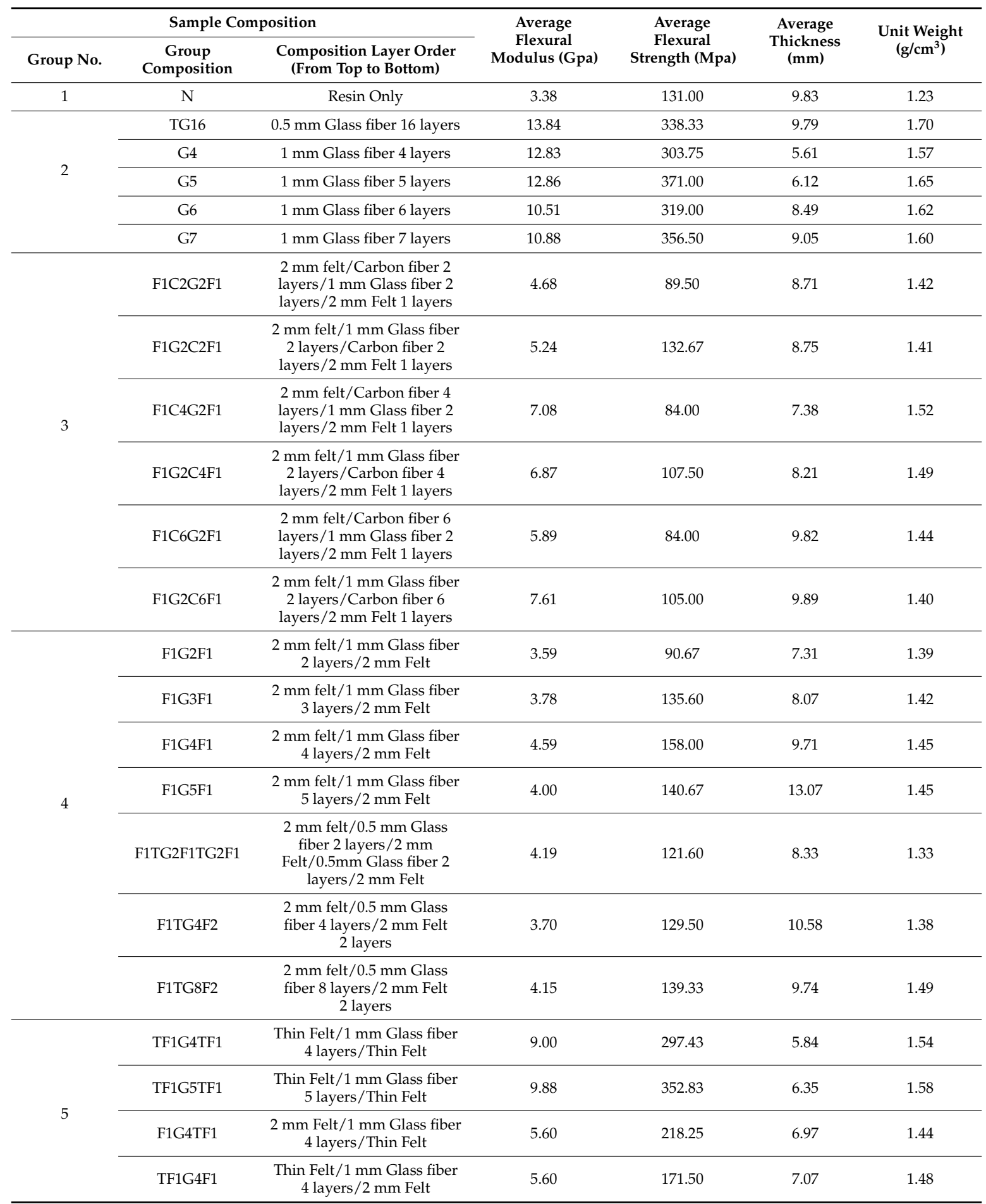

The following equations are derived to calculate the thickness of CIPP from X1. Design Consideration in ASTM F1216 [3] Appendixes. Equation (1) is for the partially deteriorated condition where groundwater pressure is loading pressure over the CIPP liner. Equation (2) is for the fully 
deteriorated condition that the existing pipe is no longer supporting external loads including groundwater and surrounding soil. When all other site conditions remain consistent, the CIPP liner thickness decreases proportionately to the one-third (1/3) fractional exponent of the value of $\mathrm{E}_{\mathrm{L}}$. According to ASTM F1216 [3], long-term modulus of elasticity $\left(\mathrm{E}_{\mathrm{L}}\right)$ is recommended as a half value (50 percent) of short-term flexural modulus. The reduction ratio is assumed 50 percent of the short-term value. For newly tested composite samples for this study, the reduction ratio follows as ASTM F1216 [3] recommends. The reduction ratio for these samples shall be determined by a creep test later. According to Equation (2), thickness of the CIPP liner is reverse proportional to 1/3 power of long-term flexural modulus value as shown in Table 3. $\mathrm{E}_{\mathrm{L}}$ for CIPP shall be eight times stronger to achieve half of the thickness of the CIPP liner.

$$
\begin{gathered}
t=\frac{D}{\sqrt[3]{\frac{2 K_{\mathrm{L}} \mathrm{C}}{\mathrm{PN}\left(1-\mathrm{v}^{2}\right)}+1}} \\
t=0.721 \mathrm{3}^{\left[\frac{\left(\frac{\mathrm{Nq}_{\mathrm{t}}}{\mathrm{C}}\right)^{2}}{\mathrm{E}_{\mathrm{L}} \mathrm{R}_{\mathrm{W}} \mathrm{B} / \mathrm{E} / \mathrm{s}}\right]}
\end{gathered}
$$

where, $t=$ thickness of CIPP, $\mathrm{D}=$ mean inside diameter of original pipe, $\mathrm{K}=$ enhancement factor of the soil and existing pipe adjacent to the new pipe, $\mathrm{E}_{\mathrm{L}}=$ long-term modulus of elasticity for CIPP, $\mathrm{C}=$ ovality reduction factor, $\mathrm{P}=$ groundwater load, $\mathrm{N}=$ factor of safety, $\mathrm{qt}=$ total external pressure on pipe, $R_{W}=$ water buoyancy factor, $B^{\prime}=$ Coefficient of elastic support, and $\mathrm{E}_{\mathrm{S}}^{\prime}=$ modulus of soil reaction.

Table 3. Thickness table.

\begin{tabular}{ccc}
\hline Thickness & Flexural Modulus & Thickness (Changing Expression) \\
\hline$t_{1}$ & $\mathrm{E}_{\mathrm{L} 1}$ & $t_{1}$ \\
$t_{2}$ & $\mathrm{E}_{\mathrm{L} 2}=2 \times \mathrm{E}_{\mathrm{L} 1}$ & $t_{2}=\frac{1}{\sqrt[3]{2}} t_{1}$ \\
$t_{3}$ & $\mathrm{E}_{\mathrm{L} 3}=8 \times \mathrm{E}_{\mathrm{L} 1}$ & $t_{3}=\frac{1}{\sqrt[3]{8}} t_{1}=\frac{1}{2} t_{1}$ \\
\hline
\end{tabular}

As a number of glass fiber layers increase, the magnitude of the applied load positively and linearly increases as shown in Figure 3. The result of the group No. 2 verifies that the glass fiber effectively reinforces its structural capacity. Samples made out of glass fiber sheets and resin positively exceed $10 \mathrm{Gpa}$ in Flexural modulus that surpasses at least six times that the minimum value proposed by ASTM F1216 [3]. Average thickness for G4 in the group No. 2 is less than $6 \mathrm{~mm}$, and unit weight is $1.57 \mathrm{~g} / \mathrm{cm}^{3}$. It verifies the effectiveness of the glass fiber reinforcement in this application. Figure 3 shows that Equations (1) and (2) are suitable to apply the design of the glass fiber reinforced CIPP liner without a significant modification.

Figure 4 presents the flexural modulus of all sample groups. Notably, carbon fiber reinforcement with glass fiber is not significantly increasing flexural modulus. Felt-Glass fiber-Carbon fiber-Felt (FGCF) composite shows the higher value of the flexural modulus than Felt-Carbon fiber-Glass fiber-Felt (FCGF). It means that glass fiber layer takes higher compressive stress than tensional stress. The effectiveness of glass fiber reinforcement between $2 \mathrm{~mm}$ regular felt layers is presented in Group No. 4 in Table 2. Hypothetically, the authors presumed that the samples in the group No. 4 and No. 2 behave alike. However, glass fibers with $2 \mathrm{~mm}$ regular felt fail to attain a sufficient level of structural reinforcement. Figure 4 indicates that $2 \mathrm{~mm}$ Felt-Glass fiber-2 mm Felt (FGF) composites is not effective as expected. The flexural modulus in the group No. 4 is only increased less than $1 \mathrm{Gpa}$ from the baseline value in the group No. 1. In addition, a combination of $0.5 \mathrm{~mm}$ thin felt and $2 \mathrm{~mm}$ felt (FGTF) shows an insignificant increment of the flexural modulus. In summary, all samples used $2 \mathrm{~mm}$ felt are incapable of increasing flexural modulus and strength as expected. The most noteworthy result is found from a composite made of multiple glass fiber layers with two thin felt layers (TFGTF) as 
shown in the group No. 5 in Table 2. Range bar for TFGTF in Figure 4 demonstrates flexural modulus results. The average modulus value is slightly lower than the fiberglass layer $(G)$, which shows the highest flexural modulus. The less felt uses in the composite, the higher flexural modulus is obtained.

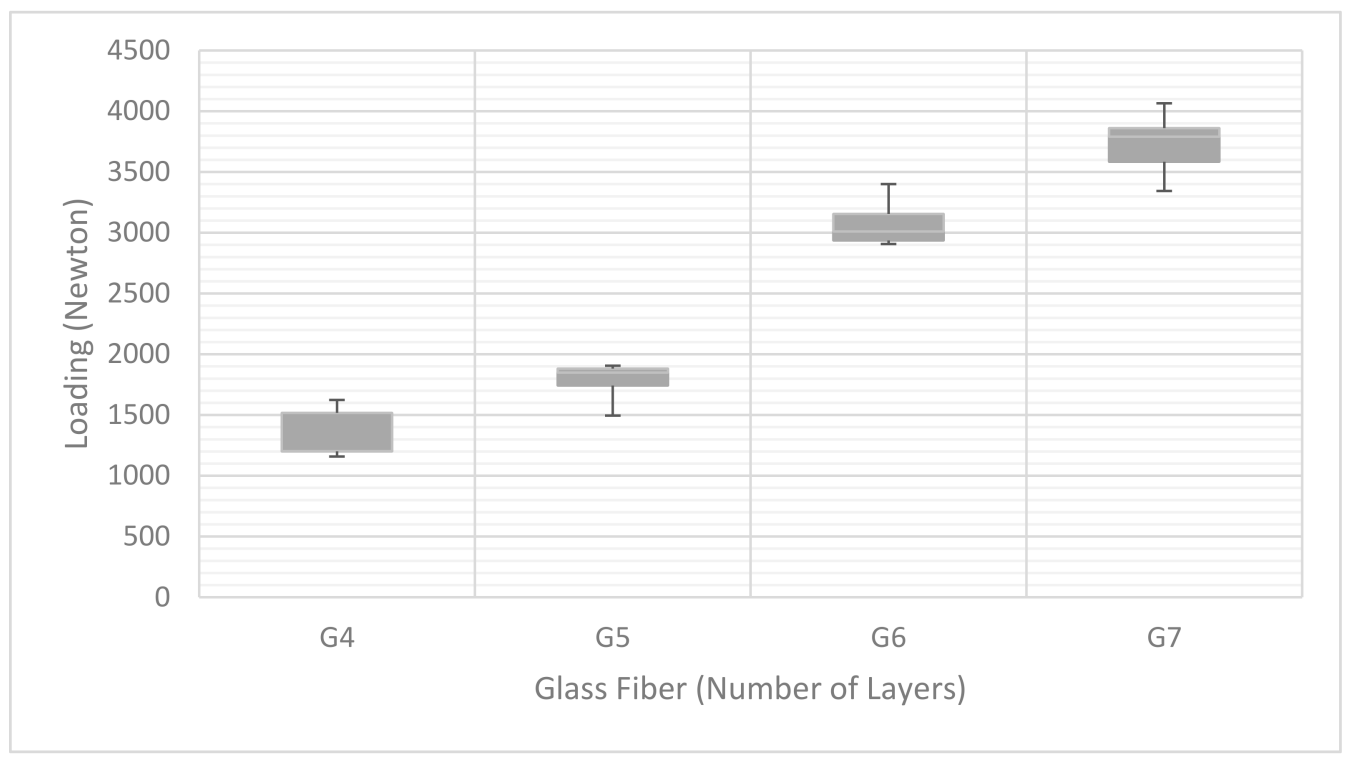

Figure 3. Load for Glass Fiber Composite Samples.

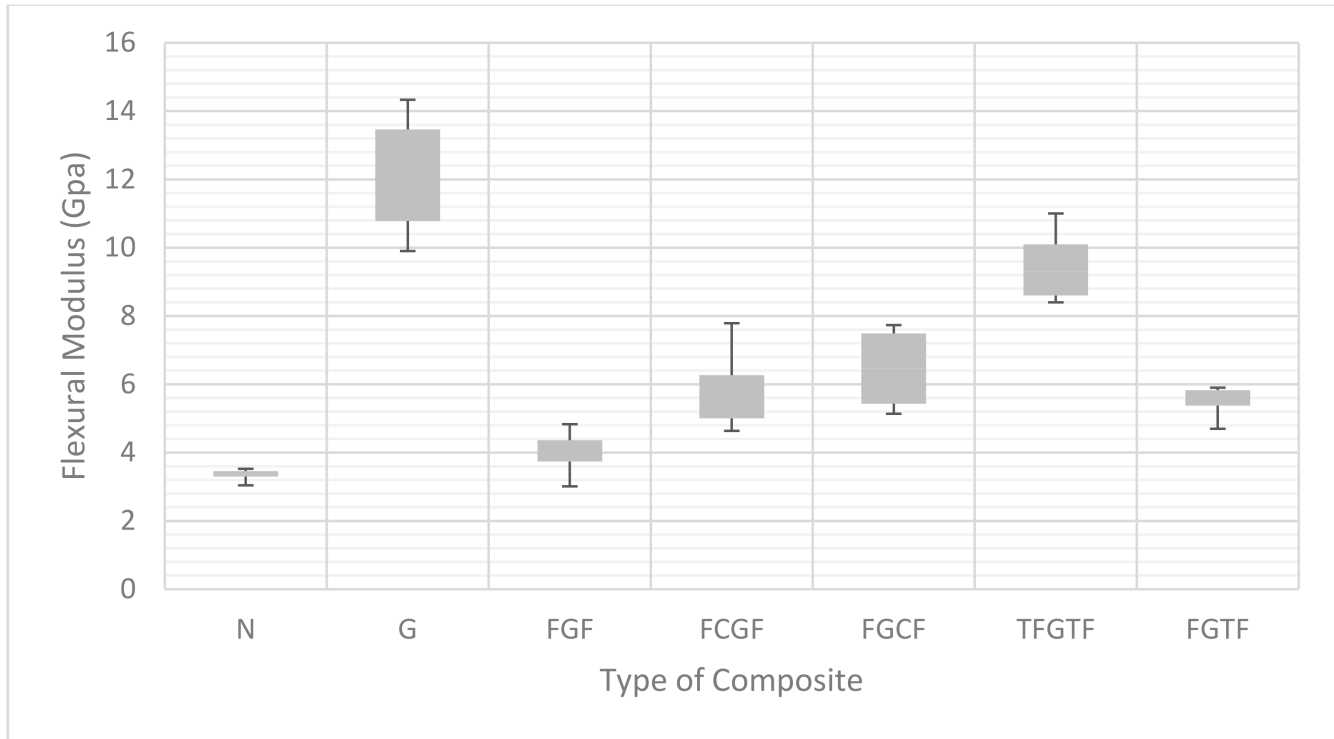

Figure 4. Summary of Flexural Modulus. Note: Nomenclature of the composite sample groups is included in Table 1.

Figure 5 presents stress-strain relations acquired from three-point bend tests. The deflection of CIPP is the decrease of the vertical diameter due to external load on the CIPP. Partially deteriorated pipe rehabilitation is not designed to withstand significant external load-bearing capacity. However, CIPP in fully deteriorated pipe rehabilitation condition should tolerate all external loads. Thus, the CIPP deflects and the deflection is used in the design process. The most design guidelines allow a maximum of 5 percent and CIPP is treated as a flexible pipe. Deflection of the pipe is related to the stiffness. Higher stiffness of the pipe means that it is less flexible and has higher flexural modulus. Figure $5 \mathrm{a}$ indicates that glass fiber composites exhibit the highest flexural strength and modulus as 
compared to all other sample groups. However, deflection at the maximum flexural stress before the fracture is significantly below five (5) percent, which ranges between 3.0 and 3.5 percent. Other sample groups using regular $2 \mathrm{~mm}$ felt layers in Figure $5 b, c$ exhibit similar deflection patterns to the resin (N). Figure 5d,e show the carbon fiber is highly stiff at the beginning, but it fails less than 3 percent deflection. Figure 6 illustrates an example of carbon fiber layered samples that fractured and clearly delaminated after three-point bend tests. It is found that the unsaturated polyester resin used for typical CIPPs is not suitable to acquire sufficient bonding strength with carbon fiber. Dong et al. [14] tested carbon fiber reinforced epoxy hybrid composites. Substituting carbon fibers in lieu of glass fibers potentially improve the flexural strength and modulus.

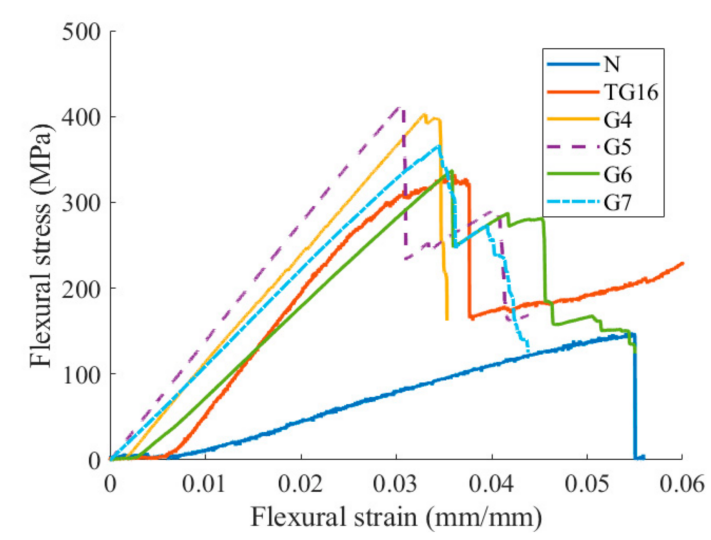

(a)

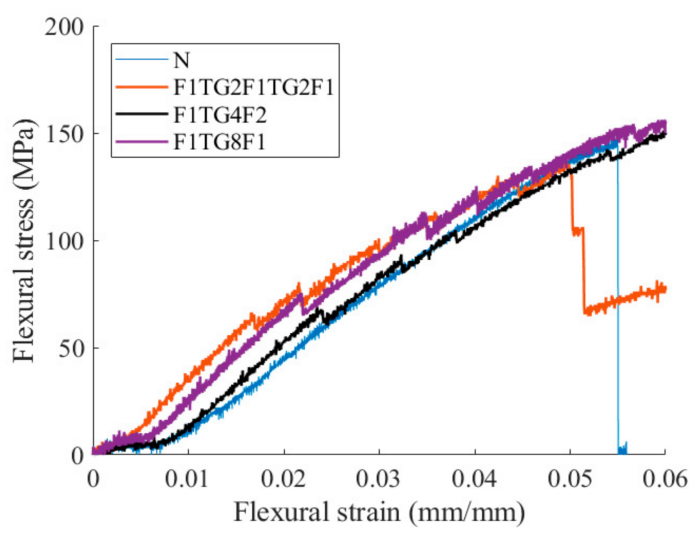

(c)

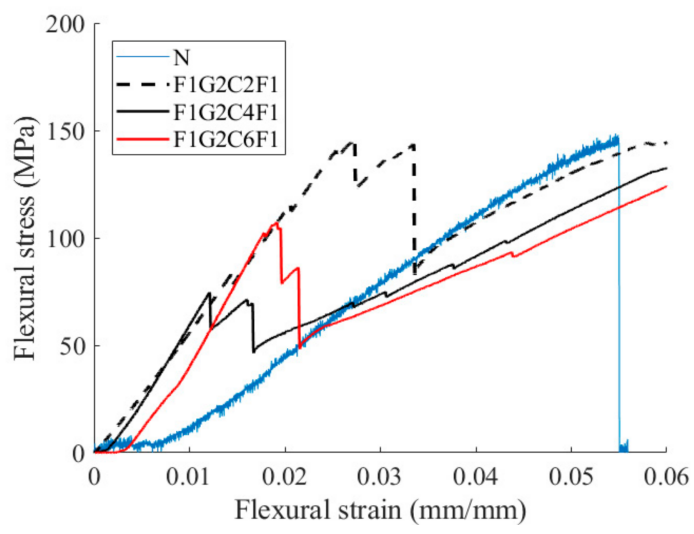

(e)

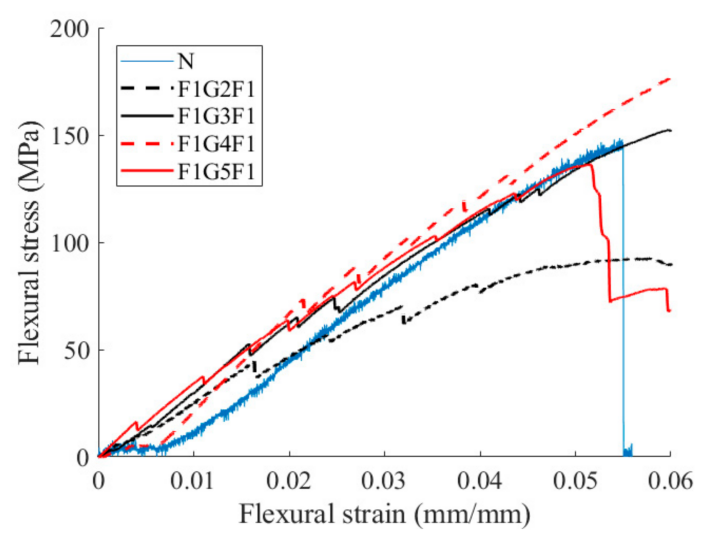

(b)

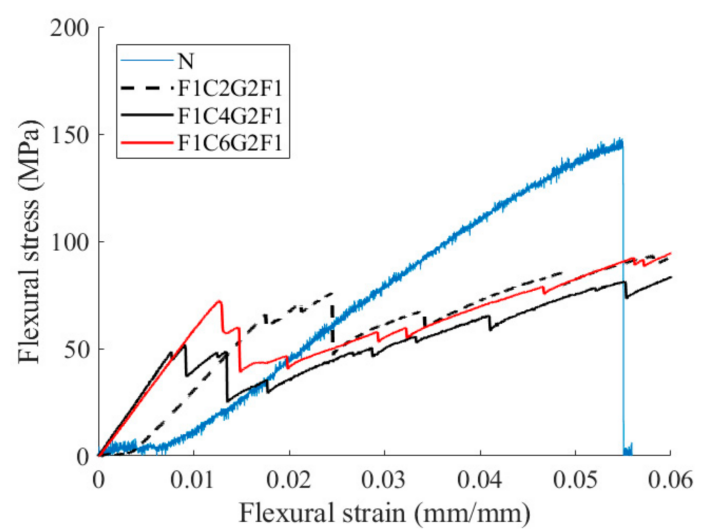

(d)

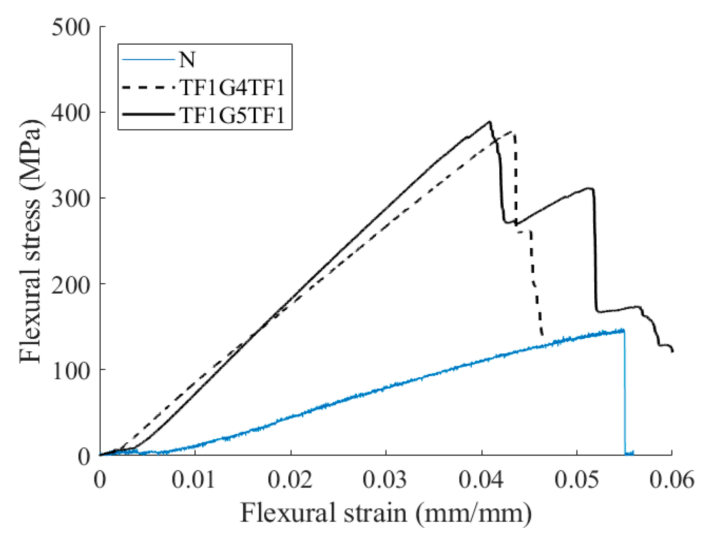

(f)

Figure 5. Stress-Strain (Deformation) Relation: (a) N: Rein; (b) G: Glass Fiber; (c) FGF: Felt-Glass Fiber-Felt; (d) FCGF: Felt-Carbon Fiber-Glass Fiber-Felt; (e) FGCF: Felt-Glass Fiber-Carbon Fiber-Felt; and (f) TFGTF: Thin Felt-Glass Fiber-Thin Felt. 


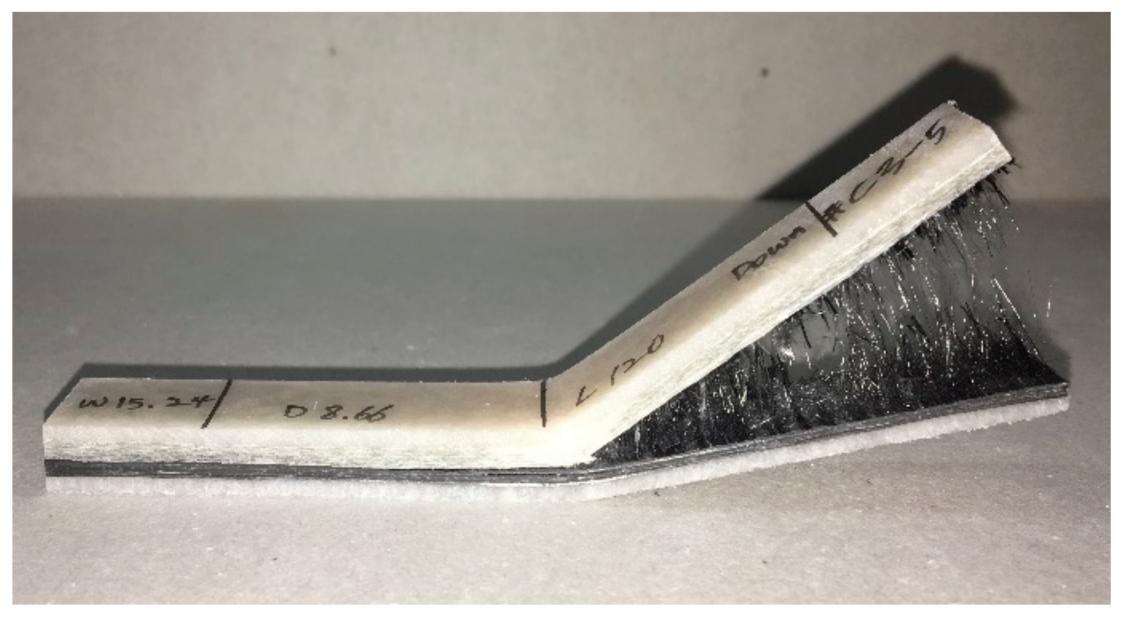

Figure 6. Carbon Fiber Fracture and Delamination.

This study was not able to verify the effectiveness of carbon fiber reinforcement. Polyester resin demonstrates relatively higher shrinkage during curing time causing cracking at the interface with carbon fiber. The bonding strength of epoxy is significantly higher than polyester resin. Therefore, the structural effect of the composite CIPP liner using polyester resin does not enhance mechanical property and the specimens were fractured at low deflection as shown in Figure 5d,e.

The stress and strain relations of a composite with thin felt and glass fiber are shown in Figure 4f. Unlike other composites, these particular composites enhance both flexural strength and stress-strain relation. The flexural strength approximately reached at $400 \mathrm{Mpa}$ and stress-strain continuously increases up to 5 percent. This implication indicates an apparent hybrid effect of combining two different materials. There is another benefit of using the thin felt as out liners. It is vital for CIPP because glass fiber layer needs a form of the container holding liquid state resin for impregnation and installation in the existing sewer pipe before the curing process. This composite shall be further studied for development of a high strength CIPP composite material technology and construct for a future CIPP pilot test.

\section{Conclusions}

This paper presents a summary of mechanical test results and a comparison study of the various composite materials for CIPP rehabilitation. A total of 122 specimens in 21 composite sample groups were made by the manual hand lay-up process in between two stainless steel plates and used normal hot water unsaturated polyester curing. Three-point bend tests were conducted in accordance with ASTM D790 [7].

Glass fiber and carbon fiber were used to enhance mechanical properties including flexural strength and modulus. Carbon fiber reinforcement with the polyester resin was unsuccessful to increase any of the proposed mechanical properties significantly. Specimens made of glass fiber increase flexural modulus up to eight times of the ASTM minimum short-term flexural modulus as the experiment desired. However, the glass fiber liner in Figure 5a fractured significantly less than 4 percent that is not intended engineering property for conventional flexible pipe materials including CIPP liner material. It means that the glass fiber liner has the highest stiffness among all samples. It can be applied to a rigid pipe rehabilitation such as concrete pipe, but not the best suitable for a flexible pipe rehabilitation such as PVC and HDPE pipes which typically allow maximum deformation at 5 percent. Another critical problem to impregnate resin in the CIPP liner and install in the construction site without the impermeable film that holds resin in the liner. Therefore, a composite layer made of the glass fiber and thin felt layers yielded the best outcomes. 
The thin felt consists of the top and bottom layers of the composite, and take approximately 20 percent of the total thickness. The thin felt layer with impermeable film coating holds resin during the impregnation and installation process while glass fiber layers increase flexural strength and modulus. This composite enhances not only mechanical properties including flexural strength also a degree of deflection above 4 percent. The additional thin felt layers improve the flexibility of the composite and exhibit slow failure mode as shown in Figure 5f. Based on the findings from this study, the authors conclude that the thin felt layer can serve a resin containment bag during resin impregnation process and an internal barrier for resin curing. Glass fiber layers significantly improve the mechanical properties. This combination of two proposed materials can be used as a composite for a high strength CIPP layer development for sewer and potentially water conveyance system rehabilitation applications.

The future research plans to seek simultaneously increasing deformation up to 5 percent and mechanical properties such as flexural strength and modulus.

Author Contributions: Conceptualization, H.W.J.; Data curation, J.K.; Formal analysis, J.K.; Investigation, J.K.; Methodology, H.W.J. and D.D.K.; Project administration, D.D.K.; Supervision, S.S.Y.; Writing一original draft, H.W.J. and D.D.K.; Writing-review and editing, S.S.Y.

Funding: This subject is supported by Korea Ministry of Environment (MOE: 2017-0007-00001) as “Public Technology Program based on Environmental Policy."

Acknowledgments: We acknowledge the anonymous reviewers for their valuable comments.

Conflicts of Interest: The authors declare no conflict of interest.

\section{References}

1. ASCE. 2017 Infrastructure Report Card-A Comprehensive Assessment of America's Infrastructure. Available online: https://www.infrastructurereportcard.org/wp-content/uploads/2016/10/2017Infrastructure-Report-Card.pdf (accessed on 24 July 2018).

2. Najafi, M.; Gokhale, S. Trenchless Technology: Pipeline and Utility Design, Construction, and Renewal; McGraw-Hill: New York, NY, USA, 2005.

3. ASTM International. Standard Practice for Rehabilitation of Existing Pipelines and Conduits by the Inversion and Curing of a Resin-Impregnated Tube. 2009. Available online: https: / / scholar.google.co.kr/scholar?hl=ko\&as_sdt=0\%2C5\&q=Standard + practice+for+rehabilitation + of + existing+pipelines+and+conduits+by+the+inversion+and+curing+of $+a+$ resin-impregnated +tube\&btnG= (accessed on 24 July 2018).

4. Allouche, E.; Alam, S.; Simicevic, J.; Sterling, R.; Condit, W.; Matthews, J.; Selvakumar, A. A pilot study for retrospective evaluation of cured-in-place pipe (cipp) rehabilitation of municipal gravity sewers. Tunn. Undergr. Space Technol. 2014, 39, 82-93. [CrossRef]

5. Water Authorities Association. Sewerage Rehabilitation Manual; Water Research Center: London, UK, 1990.

6. Standard ATV-DVWK-A 127E: Static Calculation of Drains and Sewers. 2000. Available online: https: / /dokumen.tips/documents/atv-dvwk-a-127-e-static-calculations-of-drains-and-sewers.html (accessed on 24 July 2018).

7. ASTM Inernational. Standard test methods for flexural properties of unreinforced and reinforced plastics and electrical insulating materials. Astm d790. In Annual Book of ASTM Standards; ASTM Inernational: West Conshohocken, PA, USA, 1997.

8. Riahi, A.M. Short-Term and Long-Term Mechanical Properties of Cipp Liners. Master's Thesis, University of Waterloo, Waterloo, ON, Canada, 2015.

9. Straughan, W.T.; Guice, L.K.; Mal-Duraipandian, C. Long-term structural behavior of pipeline rehabilitation systems. J. Infrastruct. Syst. 1995, 1, 214-220. [CrossRef]

10. North American Society for Trenchless Technology. Nastt's Cured-in-Place (Cipp) Good Practices Guidelines; North American Society for Trenchless Technology: Cleveland, OH, USA, 2015.

11. Nassar, R.; Yousef, M. Analysis of creep failure times of cured-in-place pipe rehabilitation liners. Tunn. Undergr. Space Technol. 2002, 17, 327-332. [CrossRef]

12. Matthews, J.C. Large-diameter sewer rehabilitation using a fiber-reinforced cured-in-place pipe. Pract. Period. Struct. Des. Constr. 2014, 20, 04014031. [CrossRef] 
13. Akinci, A.; Güleç, A.; Yilmaz, F. The Applicability of Grp and Nrp Composites in Rehabilitation of Unpressurized Pipes. In Advanced Materials Research; Trans Tech Publications: Zürich, Switzerland, 2010; pp. 563-570.

14. Dong, C.; Davies, I.J. Flexural properties of e glass and tr50s carbon fiber reinforced epoxy hybrid composites. J. Mater. Eng. Perform. 2013, 22, 41-49. [CrossRef] 